\title{
Gonadal status of male recipient mice influences germ cell development in immature buffalo testis tissue xenograft
}

\author{
Niranjan Reddy ${ }^{1}$, Ranjeet Singh Mahla ${ }^{1}$, Revanth Thathi ${ }^{1}$, Sanjay Kumar Suman ${ }^{1}$, Jedy Jose ${ }^{2}$ \\ and Sandeep Goel ${ }^{1}$ \\ ${ }^{1}$ Laboratory for the Conservation of Endangered Species and ${ }^{2}$ Animal House, Centre for Cellular and Molecular \\ Biology, Council for Scientific and Industrial Research, Uppal Road, Hyderabad 500 007, India
}

Correspondence should be addressed to S Goel; Email: sandeep@ccmb.res.in

\begin{abstract}
Growth and development of immature testis xenograft from various domestic mammals has been shown in mouse recipients; however, buffalo testis xenografts have not been reported to date. In this study, small fragments of testis tissue from 8-week-old buffalo calves were implanted subcutaneously onto the back of immunodeficient male mouse recipients, which were either castrated or left intact (non-castrated). The xenografts were retrieved and analyzed 12 and 24 weeks later. The grafted tissue survived and grew in both types of recipient with a significant increase in weight and seminiferous tubule diameter. Recovery of grafts from intact recipients 24 weeks post-grafting was significantly lower than that from the castrated recipients. Seminal vesicle indices and serum testosterone levels were lower in castrated recipients at both collection time points in comparison to the intact recipients and non-grafted intact mouse controls. Pachytene spermatocytes were the most advanced germ cells observed in grafts recovered from castrated recipients 24 weeks post-grafting. Complete spermatogenesis, as indicated by the presence of elongated spermatids, was present only in grafts from intact recipients collected 24 weeks post-grafting. However, significant number of germ cells with DNA damage was also detected in these grafts as indicated by TUNEL assay. The complete germ cell differentiation in xenografts from intact recipients may be attributed to efficient Sertoli cell maturation. These results suggest that germ cell differentiation in buffalo testis xenograft can be completed by altering the recipient gonadal status.

Reproduction (2012) 143 59-69
\end{abstract}

\section{Introduction}

Testicular xenografts from various domestic mammals in immunocompromised nude mice have been shown to cause germ cell development to varying degrees. This varies from production of spermatozoa in pigs (Honaramooz et al. 2002, 2008, Nakai et al. 2009, 2010), goats (Honaramooz et al. 2002), cats (Snedaker et al. 2004), and dogs (Abrishami et al. 2010) to less effective spermatogenic differentiation and production of elongated spermatids in bulls (Oatley et al. 2004, 2005, Rathi et al. 2005, Schmidt et al. 2006) and horses (Rathi et al. 2006). However, the mechanisms underlying these variations remain unexplained.

Xenografting of testis tissue in castrated recipient mice is a common practice. It is observed that castration of recipient mice is essential for the development of immature rhesus monkey testis xenografts, as xenografts do not develop in intact mice (Honaramooz et al. 2004). Castration of recipient mice also allows monitoring of androgen production by grafts Leydig cells, by weight, and histology of the recipient seminal vesicles, the development of which is androgen dependent
(Gosden \& Aubard 1996). In addition, removal of the recipient testes releases negative feedback on the mouse pituitary secretion of $\mathrm{FSH}$, resulting in increased levels of FSH at the time of grafting (Schlatt et al. 2003). These increased gonadotropin levels are thought to support Sertoli cell (SC) proliferation and graft development until a feedback axis is re-established between the grafted tissue and the recipient hypothalamus and pituitary. This rise in gonadotropin levels post-castration is thought to be useful, and even necessary, as a means of providing gonadotropic stimulation for the newly grafted testis tissue (Honaramooz et al. 2002, Dobrinski 2005, Paris \& Schlatt 2007, Rodriguez-Sosa \& Dobrinski 2009). Turner (1938) found that survival of homologous testicular grafts in rats was better (less degeneration, more sperm) when the recipient was castrated. However, Shinohara et al. (2002) obtained functional sperms from rabbit testis xenografts in intact mouse recipients. Similarly, recent reports described no difference in survival and development of xenografts of bull (Huang et al. 2008) and pig (Abbasi \& Honaramooz 2010) testes in both castrated and intact mouse recipients. 
Table 1 Experimental graft data.

\begin{tabular}{lcccc}
\hline $\begin{array}{l}\text { Recipient male } \\
\text { mice gonadal status }\end{array}$ & $\begin{array}{c}\text { Graft period } \\
\text { (weeks) }\end{array}$ & $\begin{array}{c}\text { No. of mice grafted } \\
\text { and analyzed }^{-12}\end{array}$ & $\begin{array}{c}\text { No. of grafts } \\
\text { recovered }^{\mathbf{a}}(\%)\end{array}$ & $\begin{array}{c}\text { No. of complete } \\
\text { functional grafts }^{\mathrm{b}}(\%)\end{array}$ \\
\hline Castrated & 12 & 6 & $91.6(33 / 36)$ & $0(0 / 33)$ \\
Intact & 24 & 5 & $93.3(28 / 30)$ & $0(0 / 28)$ \\
& 12 & 5 & $86.6(26 / 30)$ & $0(0 / 26)$ \\
\hline
\end{tabular}

*Significantly different within the column $(P<0.05)$.

${ }^{a}$ Total grafts removed divided by the total number of grafts grafted. ${ }^{b}$ Percentage of recovered grafts with elongated spermatids.

During prepubertal development, somatic and germ cells undergo a series of proliferation and differentiation to initiate the first wave of spermatogenesis. In buffalo, as in most mammals, germ cell differentiation begins with the migration of gonocytes from the center of the seminiferous tubule to a location on the basement membrane. Upon establishment on the basement membrane, gonocytes differentiate into spermatogonia (SG) and begin to proliferate. Primitive SCs are present in the sex cord of 4-week-old calves, whereas SCs are first seen in 36-week-old calves (Rana \& Bilaspuri 2004). Although spermatocytes and spermatids appear in early developmental stages, a rapid increase in their number is recorded after 144 weeks (Rana \& Bilaspuri 2004). The number of SCs is maximal in 72-week-old animals. Primitive SCs predominate in the sex cord of animals aged 4-24 weeks, SG at 36-48 weeks of age, primary spermatocytes from 60 to 120 weeks, and spermatids from 144 to 288 weeks and in older animals (Rana \& Bilaspuri 2004). In the Murrah buffalo, the most advanced germ cell types in the different age groups (weeks) in testis is gonocytes (0 and 4), SG (4 and 12), early pachytene ( 24 and 36 ), late pachytene (48), secondary spermatocytes (60 and 72), elongating spermatids (84 and 96), elongated spermatids attached to SCs (120), elongated spermatids detached from SCs (144), and spermatozoa (168 and 192) (Rana \& Bilaspuri 2004).

Buffalo testis xenografts onto recipient mice remain unreported. Testis tissue xenografts can provide an accessible in vivo model to facilitate the study of buffalo spermatogenesis. In addition, this can also serve as a useful model for developing techniques for conservation of endangered wild buffalo where testis tissue xenografts can be used for generation of viable spermatozoa from immature testis for assisted reproduction. The objective of this study was to investigate germ cell development in buffalo ectopic testis tissue xenografts in intact or castrated mouse recipients, in order to gain a better understating of early buffalo testis development. To achieve this, testis tissues from 8-week-old buffalo bulls were ectopically xenografted onto intact or castrated mice and ultimately removed at 12 and 24 weeks post-grafting and analyzed for graft development and germ cell differentiation.

\section{Results \\ Donor graft recovery, graft weight, recipient mice testosterone level, and seminal vesicle weight}

The growth of donor testicular tissues under the skin on the backs of recipient mice could be visually identified over the 24-week grafting period. The recovery of grafts from castrated and intact recipients 12 weeks postgrafting was not significantly different (Table $1 ; P>0.05$ ). Although the recovery of grafts from castrated recipients remained unchanged, the recovery of grafts from intact recipients at 24 week reduced significantly $(P<0.05)$. Functional grafts, which contained elongated spermatids, were present only in intact recipients 24 weeks post-grafting.

Buffalo testis tissue grafts were weighed at each collection time after removed from nude mice to assess the proliferation of testicular somatic cells and progression of spermatogenesis in the buffalo tissue. Average graft weight showed a significant increase in a time-dependent manner (Fig. 1A). The average weights of grafts from castrated and intact recipient mice were significantly higher than the donor tissue at 12 weeks $(P<0.05)$. However, there was no significant difference between the average weights of grafts between the castrated and intact recipient mice $(P>0.05)$. The average weights of grafts collected at 24 weeks from intact and castrated recipient mice were higher than the average graft weight from either recipient at 12 weeks $(P<0.05)$. Although graft weight from castrated recipients was numerically higher than that of intact recipients at 24 weeks, this difference was not statistically significant $(P>0.05)$.



Figure 1 Graft weights collected from intact and castrated recipient mice 12 and 24 weeks after grafting. Data are presented as mean \pm s.E.M. Bars with different letters are significantly different at $P<0.05$. 




Figure 2 (A) Serum testosterone and (B) seminal vesicle (SV) weights of non-grafted control, intact, and castrated mouse recipients xenografted with immature buffalo testis tissue at 12 and 24 weeks post-grafting. Data are presented as mean \pm s.E.M. Bars with different letters are significantly different at $P<0.05$.

Serum testosterone level in castrated recipients was significantly lower than that of intact recipients and the non-grafted intact control mice at both collection times (Fig. 2A; $P<0.05$ ). Similarly, average weights of seminal vesicles from castrated recipients were significantly lower than the seminal vesicle weight of intact recipients and the non-grafted intact control mice at 12 and 24 week collection times (Fig. 2B; $P<0.05$ ). Average weight of testes collected from intact recipient $(145.6 \pm 21.7 \mathrm{mg})$ and non-grafted intact control $(153 \pm 27.5 \mathrm{mg})$ mice did not differ significantly from each other $(P>0.05)$.

\section{Histological analysis of donor grafts}

Testis tissue xenografts showed varying degrees of germ cell differentiation. The degree of germ cell development within individual grafts ranged from tubules containing only SG to tubules containing pachytene spermatocytes, round or elongated spermatids being the most advanced germ cells (Fig. 3B-E). Eight-week-old donor seminiferous tubules contained gonocytes and SG as the most advanced germ cell types (Figs $3 \mathrm{~A}$ and $4 \mathrm{~A}$ ). At this age, gonocytes/SG were the only germ cells present in $97.2 \pm 2.8 \%$ tubules and are located mostly in the center of tubules. Grafts harvested from the castrated recipient mice at 12 weeks showed little development with the presence of gonocytes/ SG as the most advanced germ cells in $68.2 \pm 7.3 \%$ tubules with a few germ cells still located at the center of tubule (Figs 3B and 4A). At the same time point (12 weeks), grafts from intact mice contained pachytene spermatocytes as the most advanced cell type in $12.6 \pm 3.4 \%$ tubules (Figs $3 \mathrm{C}$ and $4 \mathrm{~B})$. Twenty-four weeks post-grafting, the grafts from castrated recipient mice contained pachytene spermatocytes as the most advanced germ cells in $14.9 \pm$ $3.6 \%$ tubules (Figs $3 \mathrm{D}$ and $4 \mathrm{~A}$ ). At the same collection time (24 weeks), grafts from intact recipient mice contained elongated spermatids as the most advanced germ cells in $2.6 \pm 0.7 \%$, round spermatids in $5.4 \pm 1.4 \%$, and pachytene spermatocytes in $21.9 \pm 5.4 \%$ tubules (Figs $3 \mathrm{E}$ and $4 \mathrm{~B}$ ). The percentage of degenerated tubules was significantly higher in xenografts from intact recipients compared with castrated recipients at both collection times $(P<0.05)$. In the in situ control (the 36-week-old buffalo testis), pachytene spermatocytes were the most advanced germ cells present in $21.8 \pm 4.6 \%$ tubules (Figs $3 \mathrm{~F}$ and $4 \mathrm{~A}, \mathrm{~B}$ ). Testes from intact recipients showed no difference in spermatogenic progression compared with testes from non-grafted intact control mice (data not shown).

Seminiferous tubule diameter was measured to determine the developmental potential of testis tissue in different recipient conditions. Average seminiferous tubule diameter showed a significant increase at different collection times after grafting in both recipient types (Fig. 5A). Twelve weeks after grafting, seminiferous
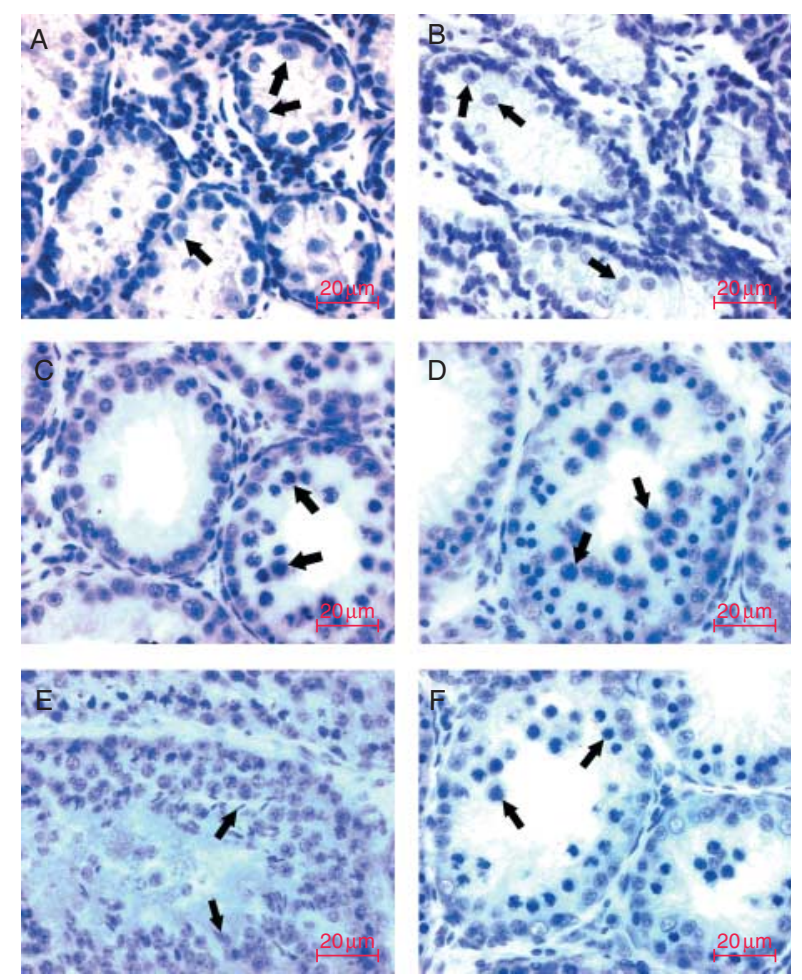

Figure 3 Histological appearance of donor, graft, and control tissue with most advanced germ cell type. Typical morphology of the most advanced germ cell types in each tubule is indicated by arrows. (A) Donor tissue from 8-week-old buffalo calf showing gonocytes/ spermatogonia. Grafts from (B) castrated, 12 weeks post-grafting containing gonocytes/spermatogonia $(C)$ intact recipient, 12 weeks post-grafting containing pachytene spermatocytes, (D) castrated recipient, 24 weeks post-grafting containing pachytene spermatocytes and (E) intact recipient, 24 weeks post-grafting containing elongated spermatids, and (F) in situ control testis tissue from 36-week-old Murrah buffalo bull shows the presence of pachytene spermatocytes. Scale bar $=20 \mu \mathrm{m}$. 

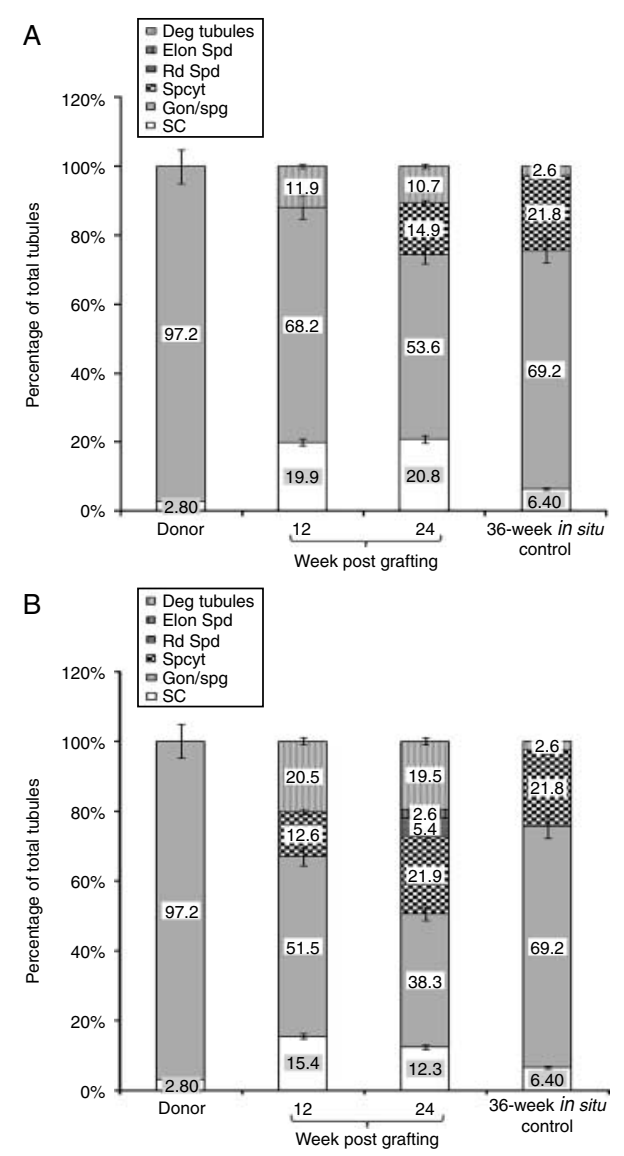

Figure 4 Percentage of seminiferous tubules with most advanced germ cell type in testis tissue xenografts per time in (A) castrated and (B) intact recipient mice. Percentage of seminiferous tubules with most advanced germ cell type in donor and 36-week in situ control tests are also presented. Deg tubules, degenerated tubules; Elon Spd, elongated spermatid; Rd Spd, round spermatid; Spcyt, pachytene spermatocytes; Gon/spg, gonocytes or spermatogonia; and SC, Sertoli cells only. Results are in mean \pm S.E.M.

tubule diameter of testis tissues collected from intact and castrated recipient mice was significantly larger than the donor testis tubules $(P<0.05)$. Moreover, grafts from intact recipients also showed significantly larger seminiferous tubule diameter than the castrated recipients $(P<0.05)$. There was a significant increase in seminiferous tubule diameter in grafts collected from both intact and castrated mouse recipients at 24 week compared with 12 week collection times $(P<0.05)$, but the diameters were not significantly different from each other at 24 weeks. Seminiferous tubule diameter of 36-week in situ control was not different from that of grafts collected from either recipient 24 weeks after grafting $(P>0.05)$.

The lumen of the seminiferous tubule was undetectable in 8-week-old donor testis (Figs $3 \mathrm{~A}$ and 5B). Initial signs of lumen formation could be seen in xenografts following 12 weeks in either recipient; however, the lumen size was significantly larger in grafts of intact mice (Fig. 5B; $P<0.05$ ). The size of the tubular lumen was larger in the grafts at 24 week collection time point in either recipient $(P<0.05)$. Although lumen diameter from castrated recipient was numerically larger than the intact recipient 24 weeks post-grafting, this difference was not statistically significant $(P>0.05)$. Tubular lumen diameter of the 36-week in situ control was not different from those of the grafts collected from either recipient type 24 weeks after grafting $(P>0.05)$.

\section{UCHL1, Mullerian inhibiting substance, and proliferating cell nuclear antigen immunostaining}

Immunohistochemical analysis for UCHL1 revealed that there was a significant decrease in the percentage of seminiferous tubules containing SG in the grafts recovered 12 and 24 weeks post-grafting, both in castrated and in intact groups, in comparison with the donor tissue and in situ control (Fig. 6A-F; $P<0.05$ ). Fresh testis tissue contained $94.2 \pm 5.8 \%$ tubules positive for UCHL1 expression (Fig. 6A). The percentage of tubules with UCHL1-positive cells, in the grafts recovered 12 weeks post-grafting, decreased to $62.2 \pm 7.3 \%$ in castrated recipients and $47.5 \pm 6.3 \%$ in intact recipients. Grafts collected 24 weeks post-grafting showed 51.6 $\pm 8.4 \%$ and $42.3 \pm 5.6 \%$ reduction in UCHL1-positive cell containing tubules in castrated and intact recipients respectively. In the in situ control testes from 36-weekold Murrah males, $87.3 \pm 6.7 \%$ tubules were positive for UCHL1-stained SG. Tubules containing only SCs, as indicated by the absence of UCHL1-positive cells, were present in donor, grafts, and control tissues. There was no significant difference in the occurrence of SC only
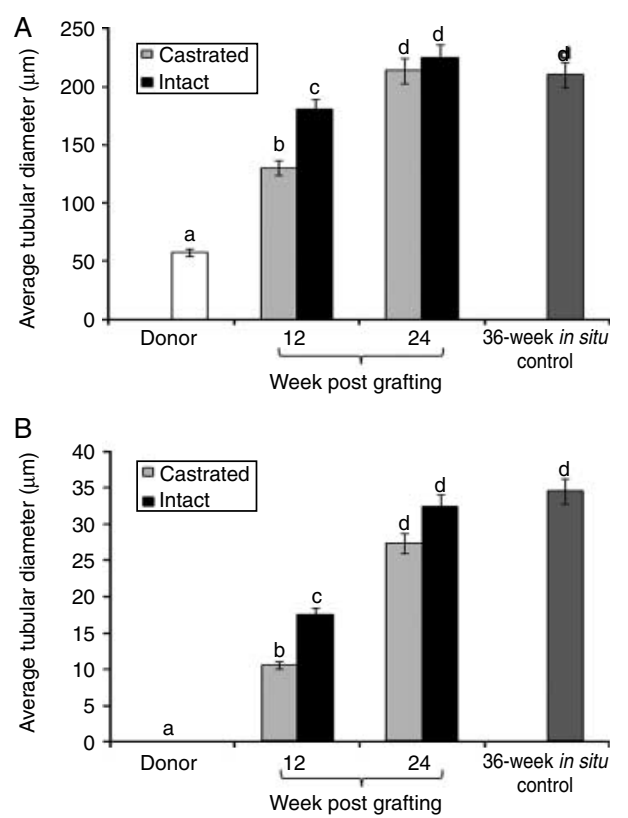

Figure 5 Average seminiferous tubule diameter $(\mathrm{A})$ and tubule lumen diameter (B) of grafts. Data are presented as mean \pm s.E.M. Bars with different letters are significantly different at $P<0.05$. 

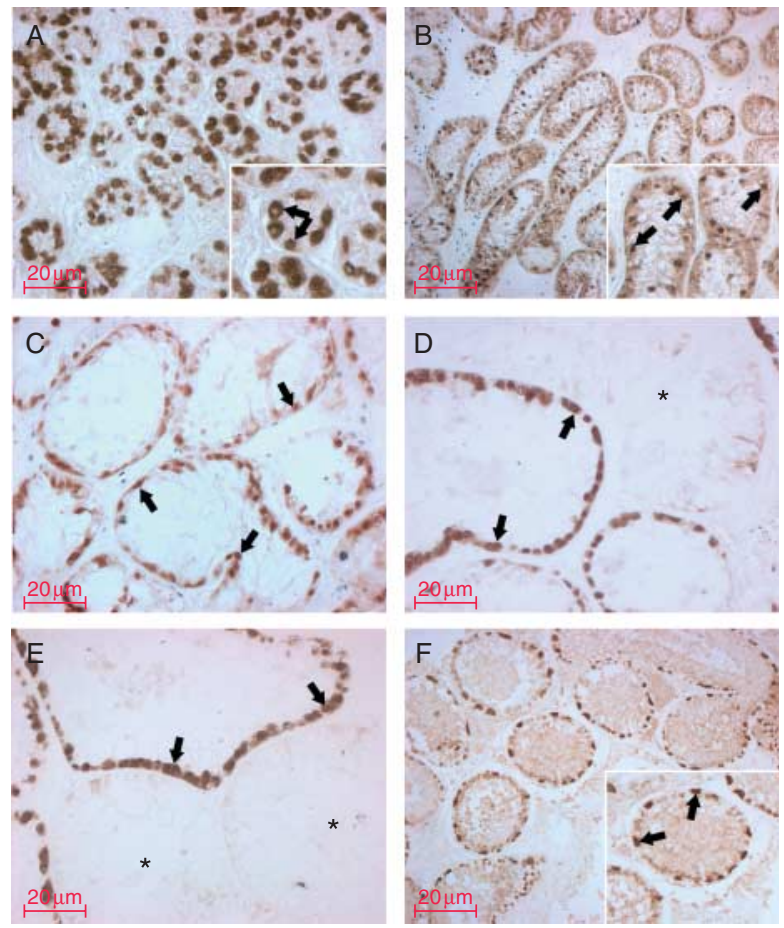

Figure 6 Gonocytes and spermatogonia identified by expression of UCHL1 in donor, grafted, and control tissue (arrows). (A) Eightweek-old donor tissue. (B) Graft from castrated recipient recovered at 12 weeks. (C) Graft form intact recipient recovered at 12 weeks. (D) Graft from castrated recipient recovered at 24 weeks. (E) Graft from intact recipient recovered at 24 weeks. (F) Control testis tissue from 36-week-old Murrah buffalo. Fewer spermatogonia were present in grafted tissues compared with donor (A) and in situ control (B) tissues. The number of Sertoli cell only tubules was higher in grafted tissue. Asterisks in panel D and E represent Sertoli cell only tubules. Scale bar $=20 \mu \mathrm{m}$.

tubules in grafts from either recipient at any collection time (Fig. 6D and E; $P>0.05$ ).

Proliferating cell nuclear antigen (PCNA) was localized to the nuclei of all dividing cells. In the donor tissue, strong PCNA staining was evident in the SCs and germ cells (Fig. 7A). Grafts collected 12 weeks postgrafting from castrated mice showed loss of PCNA staining from the SCs (as indicated by nuclear morphology and location in seminiferous tubule) but germ cells showed strong PCNA staining (Fig. 7B). In the grafts from intact mice, 12 and 24 weeks post-grafting, and castrated mice 24 weeks post-grafting, strong PCNA staining was present in meiotic-stage germ cells and in SG (Fig. 7C-E). However, PCNA-stained SCs were fewer and the staining intensity was weak (Fig. $7 \mathrm{C}-\mathrm{E}$ ). In the in situ control, strong PCNA-positive pachytene spermatocytes and SG were evident and weakly stained SCs could be identified (Fig. 7F). When the percentages of PCNA-positive cells were classified according to the cell type, donor tissues had significantly higher percentage of PCNA-positive SCs compared with germ cells (Fig. 7G). However, in the grafts collected from castrated and intact recipients at 12 and 24 weeks post-grafting, there was a significant increase in the number of PCNA-positive germ cells and significant reduction in the number of PCNA-positive SCs (Fig. 7G; $P<0.05$ ). SC proliferation was significantly lower in both castrated and intact recipient mice grafts at 12 weeks post-grafting in comparison to that of xenografts from both recipient types 24 weeks post-grafting $(P<0.05)$. Interestingly, PCNA-stained SCs and germ cells in the grafts collected
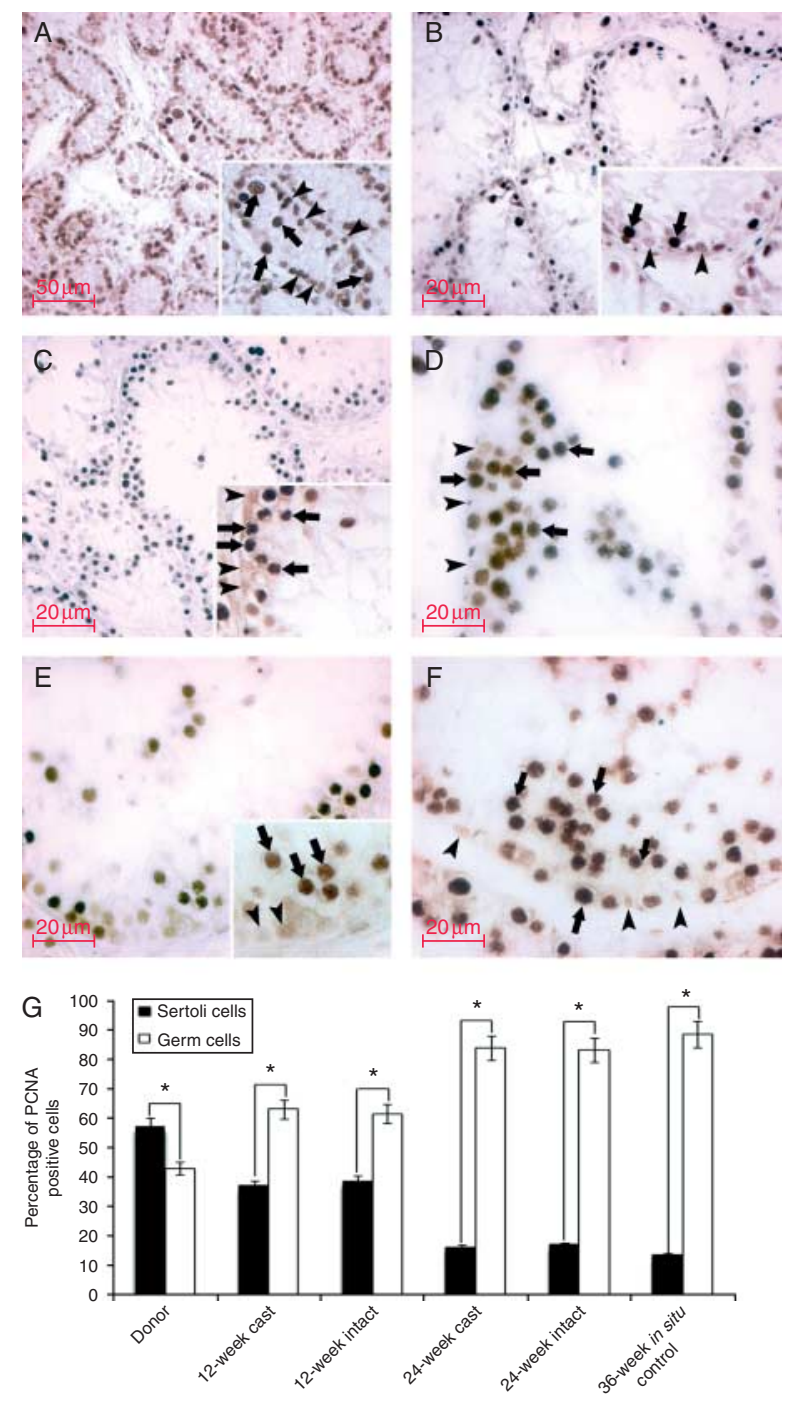

Figure 7 Expression of PCNA in donor, grafted, and 36-week in situ control testes tissue. (A) Eight-week-old donor tissue. (B) Graft from castrated recipient recovered after 12 weeks. (C) Graft from intact recipient recovered after 12 weeks. (D) Graft from castrated recipient recovered after 24 weeks. (E) Graft from intact recipient recovered after 24 weeks. (F) In situ control testis tissue from 36-week-old Murrah buffalo. PCNA-positive germ cells are indicated by arrows and the Sertoli cells by arrowheads. Insets show magnified region of section. (G) Percentage of PCNA-positive cells that were classified as germ cells or Sertoli cells according to their nuclear morphology and location in donor testis tissue and xenografts, $\left({ }^{*} P<0.05\right)$. Data represent mean \pm s.E.M. Scale bar $(A)=50 \mu \mathrm{m},(B-F)=20 \mu \mathrm{m}$. 



Figure 8 Expression of $\mathrm{AMH}$ in donor, grafted, and control tissue. (A) Eight-week-old donor tissue with strong AMH expression in Sertoli cell cytoplasm. (B) Graft from castrated recipient recovered at 12 weeks showing persisting strong AMH expression in Sertoli cell cytoplasm. $\mathrm{AMH}$ expression is notably reduced in testis xenografts collected from (C) intact recipient recovered at 12 weeks, (D) castrated recipient recovered at 24 weeks, and (E) intact recipient recovered at 24 weeks. Insets show magnified region of section where $\mathrm{AMH}$-positive cells are indicated by arrows. (F) In the control testis tissue from 36-week-old Murrah buffalo, AMH expression is absent. Scale bar $=20 \mu \mathrm{m}$.

from castrated and intact recipients were not significantly different from each other at either collection time $(P>0.05)$. In the 36-week in situ control buffalo testis, germ cell proliferation was significantly higher than the SC, which was similar to that observed in xenografts collected from either host 24 weeks after grafting.

Immunolocalization of anti-Müllerian hormone $(\mathrm{AMH}$; also known as Mullerian inhibiting substance (MIS)) in SC cytoplasm showed expression in $100 \%$ of tubules in the donor tissue as expected for immature SCs (Fig. 8A). Testis tissue grafts from castrated mice recovered at 12 weeks showed staining for $\mathrm{AMH}$ expression in the SC cytoplasm in $100 \%$ of tubules (Fig. 8B). At this collection time, the $\mathrm{AMH}$ staining intensity in SCs was strong and similar to donor tissue. The grafts recovered from intact mice, 12 weeks post-grafting, showed faint $\mathrm{AMH}$ expression in the cytoplasm of SC in $23 \%$ of tubules with no detectable staining in $77 \%$ of tubules (Fig. 8C). In the grafts collected at 24 weeks from castrated and intact recipients, $\mathrm{AMH}$ expression was weak in SCs and only 16-20\% tubules showed $\mathrm{AMH}$-positive staining (Fig. 8D and E). Interestingly, AMH-expressing tubules were fewer and $\mathrm{AMH}$ expression was weaker in SCs of grafts that had differentiated germ cells irrespective of type of recipient mice from which grafts were collected (Fig. 8C-E). In 36-week-old in situ control testis, AMH expression was undetectable in the SCs (Fig. 8F).

\section{TUNEL assay}

Grafts collected at different time points from both intact and castrated recipients were analyzed for the DNA damage in cells. Histological examination of testes revealed that TUNEL staining was present in germ cells. The percentage of TUNEL-positive tubules and number of TUNEL-positive germ cells per tubule were significantly higher in grafts recovered from intact recipients at both time points, i.e. 12 and 24 weeks post-grafting compared with grafts recovered from castrated recipients (Fig. $9 \mathrm{~A}$ and $\mathrm{B} ; P<0.05$ ). In the grafts recovered from castrated recipients, 12 weeks post-grafting, TUNEL staining was present in SG (Fig. 10A). Meiotic-stage germ cells such as spermatocytes showed TUNEL-positive staining in tubules of grafts from intact mice, 12 weeks post-grafting (Fig. 10B). Similarly, in grafts from castrated recipients, 24 weeks post-grafting, spermatocytes were positive for TUNEL


Figure 9 Estimation of DNA damage in xenografts by TUNEL assay. (A) Percentage tubules with TUNEL-positive cells in grafts recovered from donor, castrated, and intact recipients at 12 and 24 weeks post-grafting and 36-week in situ control testis. (B) Number of TUNELpositive germ cells per tubule in grafts recovered from donor, castrated, and intact recipients at 12 and 24 weeks post-grafting and 36-week in situ control testis. Data represent mean \pm s.E.M. Bars with different letters are significantly different at $P<0.05$. 

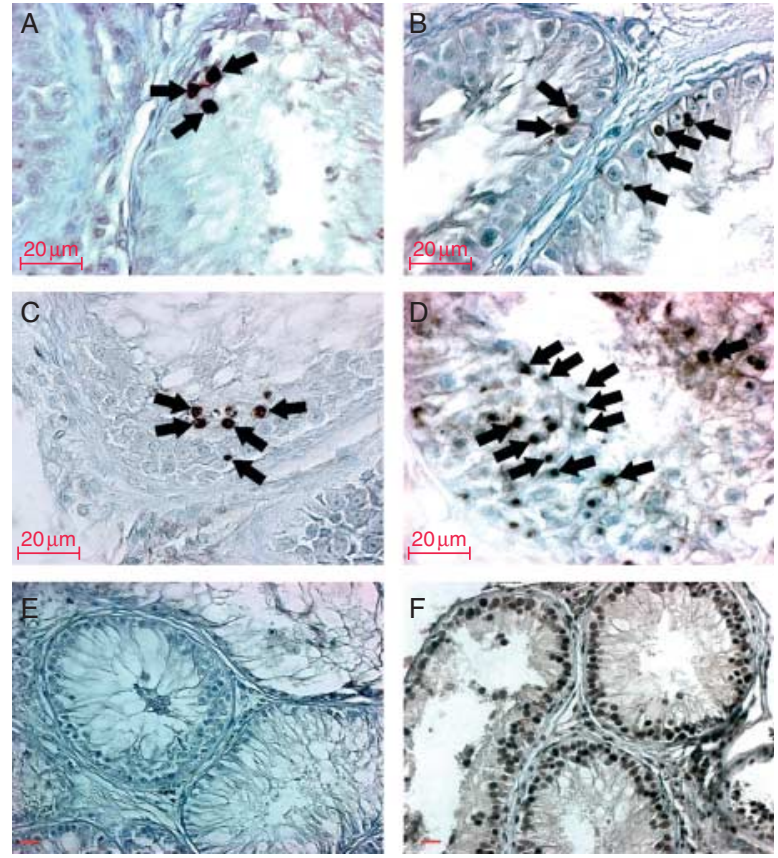

Figure 10 TUNEL staining of xenografts. The TUNEL-positive cells are indicated by arrows. Graft from, (A) castrated recipient recovered at 12 weeks, (B) intact recipient recovered at 12 weeks, (C) castrated recipient recovered at 24 weeks, and (D) intact recipient recovered at 24 weeks. (E) Negative control section shows no cells positive for TUNEL staining, and (F) TUNEL staining is present in all cells in sections of nuclease-treated positive control. Scale bar $=20 \mu \mathrm{m}$.

staining (Fig. 10C). In the grafts collected 24 weeks post-grafting from intact recipient mice, TUNEL staining was primarily present in meiotic and post-meiotic germ cells such as spermatocytes, spermatids, and rarely SG (Fig. 10D). No TUNEL-positive cells were present in negative control sections, in which the terminal deoxynucleotidyl transferase (TdT) enzyme was omitted (Fig. 10E). Positive control sections, which were treated with nuclease, showed TUNEL staining in all cells (Fig. 10F). No significant difference in the number of TUNEL-positive germ cells per tubule was observed between the testes collected from intact recipient (2.5 \pm 0.6 TUNEL-positive germ cells per tubule) and nongrafted intact control $(2.7 \pm 0.8$ TUNEL-positive germ cells per tubule) mice $(P>0.05)$.

\section{Discussion}

The objective of this study was to evaluate the establishment of spermatogenesis in ectopically xenografted testicular tissues from 8-week-old donor buffalo bulls into mouse recipients that were either castrated or intact. The results indicate that complete spermatogenesis in neonatal testis xenografts could only be established in intact recipients 24 weeks post-grafting, albeit with conspicuous DNA damage in germ cell. The findings also indicate that endocrine status of recipient mice can significantly influence the differentiation ability of germ cells and induce DNA damage in germ cells of xenografted buffalo testis.

Although the recovery of grafts was low from intact mice compared with that in castrated mice at 24 weeks, nevertheless, it did not differ significantly at 12 weeks in either group. This finding suggests that graft survival may not be completely dependent on the gonadotropin levels. The low recovery of grafts from intact recipients at 24 weeks is intriguing and could be attributed to higher plasma testosterone level compared with castrated recipients, leading to degeneration and loss of graft. This finding corroborates with the presence of significantly higher percentage of degenerative tubules in grafts recovered from intact recipients at both collection times in this study. The initial low level of gonadotropins in intact recipients can also be a possible cause of lower graft recovery.

In the current study, the weight of seminal vesicles recovered from the castrated recipients at both collection times were lower than those from intact recipients or the non-grafted intact control mice, suggesting that less bioactive testosterone is produced by the xenografted buffalo testes. This finding was further corroborated by low serum testosterone levels in castrated recipients at both collection times. Although xenografts from fetal and neonatal bovine testes in mouse recipients have been shown to maintain serum testosterone level (Rathi et al. 2005, Rodriguez-Sosa et al. 2011), equine testis xenografts produced less bioactive testosterone (Rathi et al. 2006) as indicated by the seminal gland weight. Similarly, castrated mice xenografted with infant monkey testis tissue showed lower seminal vesicle weight in gonadotropin-untreated mice compared with the treated one (Rathi et al. 2008). Plasma testosterone level is reported to be naturally low in buffalo (Sharma et al. 1984, Gulia et al. 2010), suggesting that the Leydig cells in xenografted buffalo testicular tissues are incapable of producing sufficient testosterone to maintain the normal blood level in recipient mice, subsequently leading to low seminal gland indices. Another possible cause could be that buffalo Leydig cells are less responsive to endogenous murine gonadotropin and could not be stimulated to produce sufficient bioactive testosterone.

The average weight of grafts recovered 12 and 24 weeks post-grafting was higher than that of the donor tissue irrespective of the gonadal status of recipients suggesting an increase in the length of the seminiferous tubules as a result of SC proliferation. Although there was no significant difference between the average weight of grafts recovered from castrated and intact recipients at either collection times, an effect of gonadal status on maturation was observed. At 12 week collection time, the tissue recovered from intact mouse recipients showed better tissue maturation, compared with tissues recovered from castrated mice, based on SC expression of $\mathrm{AMH}$ and the most advanced germ cell 
types observed. This indicates that gonadal status of the recipient mice could have a role in maturation of buffalo testicular xenografts. The testis tissue recovered from castrated mice 12 weeks post-grafting did not show germ cell differentiation beyond the SG stage, whereas tissue from intact mice displayed germ cell differentiation with entry into meiosis, as evidenced by the appearance of pachytene spermatocytes. Complete spermatogenesis with the appearance of elongated spermatids occurred in testis tissue collected from intact mice 24 weeks postgrafting, whereas tissue from castrated mice showed presence of pachytene spermatocytes as the most advanced germ cell, which was similar to those observed in in situ control testis. A previous report confirms the presence of pachytene spermatocytes as the most advanced germ cells in 36-week-old Murrah buffalo testis (Rana \& Bilaspuri 2004). This suggests that germ cell differentiation rate in grafts of castrated recipients mimic normal germ cell differentiation in buffalo. In this study, the grafts recovered from intact recipients showed the presence of elongated spermatids, indicating that complete germ cell differentiation is possible in grafts collected from intact recipients 24 weeks after grafting. Elongated spermatids are not detected in buffalo testis until 72-84 weeks of age (Rana \& Bilaspuri 2004, Ahmad et al. 2010). This complete differentiation of germ cells in intact recipients can again be attributed to the elevated testosterone level compared with castrated recipients. In an earlier report, elevated testosterone level in bovines has shown increased spermatogenesis and larger number of SCs per tubule cross section accompanied with increased concentrations of spermatozoa in ejaculate (Chandolia et al. 1997).

Immunolocalization of PCNA has been shown to be a validated approach for the study of cell proliferation in developing testes (Rathi et al. 2008, Rodriguez-Sosa et al. 2011). PCNA-stained SC number was similar in grafts recovered from castrated or intact recipients at a given collection time. This suggests similar SC proliferation rate in grafts collected from either recipient. However, $\mathrm{AMH}$-stained SC/tubules and intensity of $\mathrm{AMH}$ staining in SCs was higher in grafts collected from castrated recipients 12 weeks post-grafting. This suggests that the SC maturation was incomplete in grafts from castrated recipients subsequently leading to delay in germ cell differentiation. A similar finding is reported in monkey testis xenografted in mouse recipients that were left untreated with gonadotropins (Rathi et al. 2008).

Tissue maturation within the graft was also variable with some areas of the graft more mature than others. The reasons for this variation in the maturation of grafts are not apparent. It is possible that variable delivery of nutrients and hormones due to deficiencies in vascularization could have led to variable tissue development; however, this phenomenon is not observed in tissue grafts from all donor species (Honaramooz et al. 2002). Since the donor testes were pooled for the xenografting in this study, the donor effect on testis development could not be assessed.

The seminiferous tubule diameter was significantly larger in grafts recovered from either recipient 12 weeks post-grafting compared with the tubular diameter of donor tissue. This is suggestive of germ cell development and changes in SC morphology (Oatley et al. 2004, Schmidt et al. 2006). Although the seminiferous tubule and tubule lumen diameters of grafts from castrated recipients was smaller than that of the grafts collected from intact recipients at the 12-week collection time, these differences were inconspicuous at the 24-week collection time. This indicates that testicular maturation was delayed in grafts from castrated recipients compared with the intact recipients. This was also evident by the absence of differentiated germ cells in the grafts collected from castrated recipients at the 12-week collection time point. Interestingly, the average seminiferous tubule and lumen diameter of grafts from either recipient at the 24-week collection time was not different from 36-week in situ control testis. This suggests that by 24 weeks, testicular maturation in xenografts was similar in both recipient types.

The efficiency of spermatogenesis in buffalo xenografts in this study was much lower than those reported in bovine (Oatley et al. 2005, Rathi et al. 2005, Schmidt et al. 2006) and equine (Rathi et al. 2006) xenografts. The number of germ cells per tubule was lower in xenografts compared with that in the donor tissue. The low germ cell number could be a result of low germ cell division rate. The transplanted tissue pieces initially lack complete blood supply, which could be detrimental for germ cell proliferation. Once the vascular supply from the recipient mice is established, proliferation and differentiation of the surviving germ cells is supported. In grafted buffalo tissue, the germ cells never appear to recover from the initial deficit and this could likely be one of the causes leading to low sperm production in buffalo grafts. Alternatively, it could also be due to the increased rate of DNA damage in the graft leading to loss of germ cells.

Evaluation of SC maturation by AR immunostaining has been reported previously for infant monkey (Rathi et al. 2008) and fetal bovine (Rodriguez-Sosa et al. 2011) testes xenografted in mouse recipients. In this study, AR expression was present in gonocytes/SG of neonatal buffalo testis and in spermatocytes and spermatids of adult buffalo testis (Fig. 11). AR expression, therefore, could not be utilized for the evaluation of SC maturation of grafted buffalo testis tissues in this study. Elongated spermatids have been shown to express AR and the AR-specific co-regulator SNURF/RNF4 (Vornberger et al. 1994, Yan et al. 2002). In addition, there is an unpublished report about gonocytes expressing AR during neonatal life in pigs and bulls (for detail, see review by Caires et al. (2010)).

A higher degeneration of seminiferous tubules in grafts recovered from intact recipients was evident in this study. Furthermore, DNA damage was higher in germ 

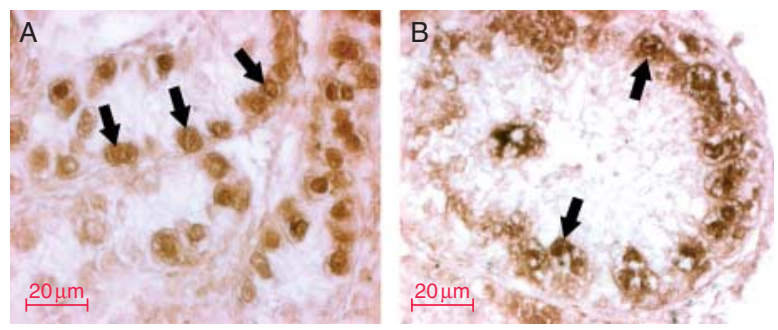

Figure 11 Expression of $A R$ in donor and adult testis tissues. (A) Eightweek-old donor testis tissue. (B) Two-year-old Murrah buffalo testis. Note that AR staining is present in gonocytes/spermatogonia (A, arrows) and in spermatocytes (B, arrows). Scale bar $=20 \mu \mathrm{m}$.

cells of xenografts recovered from intact recipients than in germ cells collected from castrated recipients at both collection time points. This is in agreement with the results of a study by Turner (1938), which reported that homologous testicular grafts in rats showed more degeneration when the recipients were non-castrated. In this study, the testes recovered from intact recipients showed no difference with respect to testis weight, spermatogenic progression, and TUNEL-positive germ cells when compared with the non-grafted intact control mice testes. This suggests that the gonadotropin levels in intact mouse recipients were within normal limits. Buffalo naturally have low serum testosterone level (an average of $0.6 \pm 0.2 \mathrm{ng} / \mathrm{ml}$ in sexually mature males; Gunarajasingam et al. 1985), which is significantly lower than that of mice $(\sim 2-5 \mathrm{ng} / \mathrm{ml}$; Steenstra et al. 1989). We hypothesize that exposing buffalo testes to an environment of elevated testosterone level leads to complete germ cell differentiation accompanied with SC maturation albeit with enhanced seminiferous tubule degeneration and DNA damage in germ cell. Fragmentation of germ cell DNA is reported to be induced in monkey testis by high dose of testosterone administration (Zhou et al. 2002, Zhang et al. 2003). This induction of DNA damage is believed to be as a result of endogenous testosterone withdrawal after injection of high dose of exogenous testosterone. The role of anti-apoptotic proteins such as BCL2 (Zhang et al. 2003) and HSP70-2 (Zhou et al. 2002) is also implicated in induction of DNA damage in germ cells such as spermatocytes and spermatids in these studies. It is quite likely that similar mechanism exists in buffalo testis xenografted in intact mice that may be playing a role in regulating DNA damage in germ cell, which needs to be validated further.

In summary, this study describes buffalo testis xenografting in immunocompromised mouse recipients for the first time. The gonadal status of recipient mice significantly influences buffalo graft maturation and germ cell differentiation. The findings from this research would provide novel model for manipulation of spermatogenic cycle in species where germ cell development is slow or delayed without administration of exogenous hormones.

\section{Materials and Methods}

\section{Donor testis tissue}

Donor water buffalo (Bubalus bubalis; Borghese \& Mazzi 2005) testes from sexually immature male calves (aged 8 weeks) of Murrah breed and testes from 36-week-old water buffalo bulls of same breed (used as in situ control) were collected from a local slaughterhouse ( $n=3$ for each age group). Testes were transported in DMEM/F12 containing hepes, antibiotics, and antimycotic on ice to the laboratory within an hour. Testis tissues from 36-week-old buffalo testes were fixed for histology in Bouin's solution, immediately after arrival to the laboratory. Testes from immature buffalo calves were washed several times with PBS and tunica albugenia and other connective tissues were removed. Testis parenchymal tissues were cut into smaller pieces from all three animals and pooled. The testis pieces were placed in DMEM/F12-hepes on ice until the time of grafting. A few testis pieces were preserved in Bouin's fixative for histological analysis.

\section{Procedure for xenografting of testis tissue in recipient mice}

Six pieces of donor testis tissue were ectopically grafted onto the back of castrated or intact (non-castrated) immunodeficient male nude mice (nu/nu Balb/c, 6-8 weeks old). The details of the number of mice used are given in Table 1 . Briefly, mice were anesthetized with ketamine $(0.1 \mathrm{mg} / \mathrm{kg}$ body weight $(\mathrm{BW}))$ and xylazine $(0.5 \mathrm{mg} / \mathrm{kg} \mathrm{BW})$ in sterile physiological saline. For castration of recipient mice, a ventral medial incision was given in the abdomen and the testes were removed following which the peritoneum and skin sutured closed using absorbable suture (Ethicon, Somerville, NJ, USA). During the same surgery, each mouse received three incisions ( $\sim 5 \mathrm{~mm}$ ) on each side of the back (total six incisions). One fragment of testis tissue ( $\sim-10 \mathrm{mg}$ each) was inserted through each incision. The incisions were sutured closed and the mice were allowed to recover and returned to their cages. Similar procedure was followed for xenografting of testis tissues in intact mice except that their testes were left intact. Animals were handled and treated in accordance with the Institutional Animals Care and Use Committee.

\section{Recovery and analysis of xenografts}

At 12 and 24 weeks post-grafting, the recipient mice were killed by $\mathrm{CO}_{2}$ inhalation. Grafts were recovered, weighed, and fixed in Bouin's solution followed by three changes of $70 \%$ ethanol before being processed for histology. After processing, the grafts were embedded in paraffin, sectioned (7 $\mu \mathrm{m}$ thick), stained with hematoxylin, dehydrated, mounted in Vectamount (Vector Laboratories, Burlingame, CA, USA), and observed under a Zeiss Axioplan 2 microscope (Carl Zeiss AG, Gottingen, Germany). In each graft, all seminiferous tubule cross sections were examined for the status of testicular maturation by measuring the seminiferous tubule and lumen diameter. The seminiferous tubule cross sections that showed one or more openings in the center, the openings were considered as the lumen. Seminiferous tubule diameter was 
determined for all round seminiferous tubule cross sections within a graft cross section and averaged per mouse. The seminiferous tubule and lumen diameters were measured using AxioVision Software (release 4.7, Carl Zeiss AG) from digital images taken along each axis. Spermatogenesis was assessed by examining the most advanced germ cell type in the xenograft and differentiated germ cells were identified by their morphology and location in the seminiferous tubule. The percentage of tubules with the most advanced germ cell type was presented. The percentage of seminiferous tubules and degenerated tubules within a graft was also presented. The tubules, which were collapsed and did not contain distinct cell type, were considered degenerated. Approximately, 10-15 sections per graft and 80-100 tubules were counted for evaluation of data. Testes from intact recipients and nongrafted intact control mice were also collected, weighed, fixed, and processed for histology as described above.

\section{Recipient mouse analysis}

Seminal vesicles from all recipient mice were weighed to assess the bioactive testosterone level in circulation (Honaramooz et al. 2002, 2004, Schlatt et al. 2003). Average weight of seminal vesicles from non-grafted intact adult males (nu/nu Balb/c, 8-12 weeks old) was taken as control $(n=8)$. Blood was collected from recipient mice at the time of killing by cardiac puncture and serum was subsequently collected by centrifugation. Blood from non-grafted intact adult males was used as control. Serum samples were then analyzed for testosterone concentration using a commercial kit (CAN-TE-250; Diagnostics Biochem Canada, Inc., London, ON, Canada).

\section{UCHL1, AMH, and PCNA immunostaining of grafted testes sections}

The testis sections were stained with UCHL1/PGP 9.5 (ubiquitin carboxyterminal hydrolase L1) to mark gonocytes/SG using a procedure described previously (Goel et al. 2010). The testis sections were also stained with AMH to assess the SC maturation and PCNA to evaluate cell proliferation in seminiferous tubules of xenografts. Dilutions of primary and secondary antibodies were done in PBS with 1\% BSA (Sigma). Briefly, after de-paraffinization and rehydration, sections were blocked with $10 \%$ fetal bovine serum (Gibco) and 3\% BSA in PBS for $30 \mathrm{~min}$, incubated with rabbit anti-UCHL1 antibody (1: 500; Dako, San Antonio, TX, USA), mouse anti-AMH (1:300; Santa Cruz Biotechnology, Inc., Santa Cruz, CA, USA), or rabbit-anti-PCNA antibody (1:200; US biological, Swampscott, MA, USA) overnight at $4{ }^{\circ} \mathrm{C}$, washed several times with PBS, incubated with $3 \% \mathrm{H}_{2} \mathrm{O}_{2}$ for 10 min, washed three times with PBS, incubated with goat anti-rabbit or goat antimouse HRP-conjugated secondary antibody (Calbiochem, Darmstadt, Germany; 1: 200) for $30 \mathrm{~min}$ at $37^{\circ} \mathrm{C}$, rinsed three times with PBS, incubated for 3-5 min in DAB substrate kit (Vector Laboratories) according to the manufacture's instruction, rinsed thoroughly in distilled water, and mounted. Negative control sections were incubated in 1\% BSA in PBS without antibody. In tissue sections that were stained for
UCHL1, tubule cross sections were scored for the presence of UCHL1-positive cells. PCNA-stained tubule cross sections were scored for the presence of PCNA-positive germ cells and SCs (distinguished by typical nuclear morphology and location in the seminiferous tubules) in each section. $\mathrm{AMH}-$ stained sections were scored based on the number of seminiferous tubules containing $\mathrm{SCs}$ positive for $\mathrm{AMH}$ staining and the intensity of $\mathrm{AMH}$ staining in SCs in the tubules. An average of 50-100 tubule cross sections per recipient mouse was examined.

\section{Assessment of DNA damage in xenografts by TUNEL assay}

Grafted testis tissues were analyzed by a TUNEL method for assessing DNA damage. Bouin's fixed testis sections were dewaxed, rehydrated, and washed in deionized water and analyzed using TACS 2 TdT In Situ Apoptosis Detection Kit (Trevigen, Inc., Gaithersburg, MD, USA) according to the manufacturer's protocol. Slides were counterstained with methyl green and dehydrated in graded alcohol solutions. The negative control sections were incubated with label solution without TdT enzyme and positive control sections were treated with TACS-Nuclease to generate DNA breaks. Testes from intact recipients and non-grafted intact control mice were also analyzed for DNA damage. The number of TUNEL-positive cells was counted in 100-150 tubules and the percentage of tubules that were TUNEL positive (showing at least one TUNEL-positive cell) was determined.

\section{Statistical analyses}

The results are presented as mean \pm s.E.M. The statistical analysis was conducted using ANOVA. Differences were determined by analyzing the data with Fisher's PSLD test for significance between the means. The level of significance was set at $P<0.05$.

\section{Declaration of interest}

The authors declare that there is no conflict of interest that could be perceived as prejudicing the impartiality of the research reported.

\section{Funding}

This work was supported by grants from Department of Biotechnology (BT/PR 10908/MED/31/35/2008) and Department of Science and Technology (DST/INT/JAP/P-72/09).

\section{Acknowledgements}

The authors would like to thank Mr B Prabhu for assistance in collecting testes. Dr Deepali Garg is acknowledged for a critical reading of the manuscript. 


\section{References}

Abbasi S \& Honaramooz A 2010 Effects of recipient mouse strain, sex and gonadal status on the outcome of testis tissue xenografting. Reproduction, Fertility, and Development 22 1279-1286. (doi:10. 1071/RD10084)

Abrishami M, Abbasi S \& Honaramooz A 2010 The effect of donor age on progression of spermatogenesis in canine testicular tissue after xenografting into immunodeficient mice. Theriogenology 73 512-522. (doi:10.1016/j.theriogenology.2009.09.035)

Ahmad N, Umair S, Shahab M \& Arslan M 2010 Testicular development and establishment of spermatogenesis in Nili-Ravi buffalo bulls. Theriogenology 73 20-25. (doi:10.1016/j.theriogenology.2009.06.034)

Borghese A \& Mazzi M 2005 Buffalo population and strategies in the world. In Buffalo Production and Research, REU Technical Series 67, pp 1-40. Ed. A Borghese. Rome: Food and Agriculture Organization of the United Nations.

Caires K, Broady J \& McLean D 2010 Maintaining the male germline: regulation of spermatogonial stem cells. Journal of Endocrinology 205 133-145. (doi:10.1677/JOE-09-0275)

Chandolia RK, Honaramooz A, Bartlewski PM, Beard AP \& Rawlings NC 1997 Effects of treatment with LH releasing hormone before the early increase in $\mathrm{LH}$ secretion on endocrine and reproductive development in bull calves. Journal of Reproduction and Fertility 111 41-50. (doi:10. 1530/jrf.0.1110041)

Dobrinski I 2005 Germ cell transplantation and testis tissue xenografting in domestic animals. Animal Reproduction Science 89 137-145. (doi:10.1016/j.anireprosci.2005.06.020)

Goel S, Reddy N, Mandal S, Fujihara M, Kim SM \& Imai H 2010 Spermatogonia-specific proteins expressed in prepubertal buffalo (Bubalus bubalis) testis and their utilization for isolation and in vitro cultivation of spermatogonia. Theriogenology 74 1221-1232. (doi:10. 1016/j.theriogenology.2010.05.025)

Gosden RG \& Aubard Y 1996 Transplantation of testicular tissue. In Transplantation of Ovarian and Testicular Tissues, pp 89-97. Eds RG Gosden \& Y Aubard. Texas: Landes Company and Chapman \& Hall.

Gulia S, Sarkar M, Kumar V, Meyer HH \& Prakash BS 2010 Divergent development of testosterone secretion in male zebu (Bos indicus) and crossbred cattle (Bos indicus $\times$ Bos taurus) and buffaloes (Bubalus bubalis) during growth. Tropical Animal Health and Production 42 1143-1148. (doi:10.1007/s11250-010-9538-x)

Gunarajasingam D, Rajamahendran R, Downey BR \& Laguë PC 1985 Testosterone secretion in young and adult buffalo bulls. Theriogenology 24 185-195. (doi:10.1016/0093-691X(85)90182-7)

Honaramooz A, Snedaker A, Boiani M, Scholer H, Dobrinski I \& Schlatt S 2002 Sperm from neonatal mammalian testes grafted in mice. Nature 418 778-781. (doi:10.1038/nature00918)

Honaramooz A, Li MW, Penedo MCT, Meyers S \& Dobrinski I 2004 Accelerated maturation of primate testis by xenografting into mice. Biology of Reproduction 70 1500-1503. (doi:10.1095/biolreprod.103. 025536)

Honaramooz A, Cui XS, Kim NH \& Dobrinski I 2008 Porcine embryos produced after intracytoplasmic sperm injection using xenogeneic pig sperm from neonatal testis tissue grafted in mice. Reproduction, Fertility, and Development 20 802-807. (doi:10.1071/RD08093)

Huang S, Sartini BL \& Parks JE 2008 Spermatogenesis in testis xenografts grafted from pre-pubertal Holstein bulls is re-established by stem cell or early spermatogonia. Animal Reproduction Science 103 1-12. (doi:10.1016/j.anireprosci.2006.11.018)

Nakai M, Kaneko H, Somfai T, Maedomari N, Ozawa M, Noguchi J, Kashiwazaki N \& Kikuchi K 2009 Generation of porcine diploid blastocysts after injection of spermatozoa grown in nude mice. Theriogenology 72 2-9. (doi:10.1016/j.theriogenology.2008.10.020)

Nakai M, Kaneko H, Somfai T, Maedomari N, Ozawa M, Noguchi J, Ito J, Kashiwazaki N \& Kikuchi K 2010 Production of viable piglets for the first time using sperm derived from ectopic testicular xenografts. Reproduction 139 331-335. (doi:10.1530/REP-09-0509)

Oatley JM, de Avila DM, Reeves JJ \& McLean DJ 2004 Spermatogenesis and germ cell transgene expression in xenografted bovine testicular tissue. Biology of Reproduction 71 494-501. (doi:10.1095/biolreprod.104. 027953)
Oatley JM, Reeves JJ \& McLean DJ 2005 Establishment of spermatogenesis in neonatal bovine testicular tissue following ectopic xenografting varies with donor age. Biology of Reproduction 72 358-364. (doi:10.1095/ biolreprod.104.030783)

Paris MC \& Schlatt S 2007 Ovarian and testicular tissue xenografting: its potential for germline preservation of companion animals, nondomestic and endangered species. Reproduction, Fertility, and Development 19 771-782. (doi:10.1071/RD07038)

Rana BK \& Bilaspuri GS 2004 A quantitative study of seminiferous tubular cells in the developing Murrah buffalo testis. Veterinary Journal 167 95-103. (doi:10.1016/S1090-0233(03)00029-7)

Rathi R, Honaramooz A, Zeng W, Schlatt S \& Dobrinski I 2005 Germ cell fate and seminiferous tubule development in bovine testis xenografts. Reproduction 130 923-929. (doi:10.1530/rep.1.00912)

Rathi R, Honaramooz A, Zeng W, Turner R \& Dobrinski I 2006 Germ cell development in equine testis tissue xenografted into mice. Reproduction 131 1091-1098. (doi:10.1530/rep.1.01101)

Rathi R, Zeng W, Megee S, Conley A, Meyers S \& Dobrinski I 2008 Maturation of testicular tissue from infant monkeys after xenografting into mice. Endocrinology 149 5288-5296. (doi:10.1210/en.2008-0311)

Rodriguez-Sosa JR \& Dobrinski I 2009 Recent developments in testis tissue xenografting. Reproduction 138 187-194. (doi:10.1530/REP-09-0012)

Rodriguez-Sosa JR, Rathi R, Wang Z \& Dobrinski I 2011 Development of bovine fetal testis tissue after ectopic xenografting in mice. Journal of Andrology 32 271-281. (doi:10.2164/jandrol.110.010322)

Schlatt S, Honaramooz A, Bioani M, Schöler RH \& Dobrinski I 2003 Progeny from sperm obtained after ectopic grafting of neonatal mouse testes. Biology of Reproduction 68 2331-2335. (doi:10.1095/biolreprod.102.014894)

Schmidt JA, de Avila JM \& McLean DJ 2006 Grafting period and donor age affect the potential for spermatogenesis in bovine ectopic testis xenografts. Biology of Reproduction 75 160-166. (doi:10.1095/biolreprod.105.049825)

Sharma IJ, Agarwal SP, Agarwal VK \& Dwaraknath PK 1984 Changes in profiles of serum sex steroids of male buffaloes from birth to maturity. Theriogenology 22 175-186. (doi:10.1016/0093-691X(84)90430-8)

Shinohara T, Inoue K, Ogonuki N, Kanatsu-Shinohara M, Miki H, Nakata K, Kurome M, Nagashima H, Toyokuni S, Kogishi K et al. 2002 Birth of offspring following transplantation of cryopreserved immature testicular pieces and in vitro microinsemination. Human Reproduction 17 3039-3045. (doi:10.1093/humrep/17.12.3039)

Snedaker AK, Honaramooz A \& Dobrinski I 2004 A game of cat and mouse: xenografting of testis tissue from domestic kittens results in complete cat spermatogenesis in a mouse host. Journal of Andrology 25 926-930.

Steenstra R, Neblett H \& Teuscher C 1989 Serum testosterone (T) levels in $B A L B / C B y J$ and $B A L B / C J$ substrain mice: potential relationship with differential susceptibility to experimental allergic orchitis (EAO). Autoimmunity 2 285-289. (doi:10.3109/08916938908997154)

Turner CD 1938 Intra-ocular homotransplantations of prepubertal testes in the rat. American Journal of Anatomy 63 101-159. (doi:10.1002/aja. 1000630105)

Vornberger W, Prins G, Musto NA \& Suarez-Quian CA 1994 Androgen receptor distribution in rat testis: new implications for androgen regulation of spermatogenesis. Endocrinology 134 2307-2316. (doi:10. 1210/en.134.5.2307)

Yan W, Hirvonen-Santti SJ, Palvimo JJ, Toppari J \& Janne OA 2002 Expression of the nuclear RING finger protein SNURF/RNF4 during rat testis development suggests a role in spermatid maturation. Mechanisms of Development 118 247-253. (doi:10.1016/S0925-4773(02)00261-7)

Zhang ZH, Zhou XC, Wei P, Hu ZY \& Liu YX 2003 Expression of Bcl-2 and Bax in rhesus monkey testis during germ cell apoptosis induced by testosterone undecanoate. Archives of Andrology 49 439-447. (doi:10. 1080/713828255)

Zhou XC, Zhang ZH, Hu ZY, Zou RJ \& Liu YX 2002 Expression of Hsp70-2 in rhesus monkey testis during germ cell apoptosis induced by testosterone undecanoate. Contraception 66 377-382. (doi:10.1016/ S0010-7824(02)00357-8)

Received 8 August 2011

First decision 31 August 2011

Revised manuscript received 25 October 2011

Accepted 31 October 2011 